\title{
CHANGING HEALTH TECHNOLOGY ASSESSMENT PARADIGMS?
}

Don Husereau

Institute of Health Economics, School of Epidemiology, Public Health and Preventive Medicine, University of Ottawa, University for Health Sciences, Medical Informatics and Technology

dhusereav@ihe.ca

Chris Henshall

Health Economics Research Group, Brunel University London
Laura Sampietro-Colom

Hospital Clinic

Sarah Thomas

Wessex Institute Enterprise and Partnerships, University of Southampton

Objectives: Health technology assessment (HTA) has to innovate to best support changing health system environments and to help provide access to valuable innovation under fiscal constraint.

Methods: Issues associated with changing HTA paradigms were identified through scoping and explored through deliberation at a meeting of industry and HTA leaders.

Results: Five broad areas of change (engagement, scientific dialogue, research prioritization, adaptive approaches, and real world data) were identified. The meeting focused on two themes derived from these: re-thinking scientific dialogue and multi-stakeholder engagement, and re-thinking value, affordability, and access. Earlier and ongoing engagement to steer the innovation process and help achieve appropriate use across the technology lifecycle was perceived as important but would be resource intensive and would require priority setting. Patients need to be involved throughout, and particularly at the early stages. Further discussion is needed on the type of body best suited to convening the dialogue required. There was agreement that HTA must continue to assess value, but views differed on the role that HTA should play in assessing affordability and on appropriate responses to challenges around affordability. Enhanced horizon scanning could play an important role in preparing for significant future investments.

Conclusions: Early and ongoing multi-stakeholder engagement and revisiting approaches to valuing innovation are required. Questions remain as to the most appropriate role for HTA bodies. Changing HTA paradigms extend HTA's traditional remit of being responsive to decision-makers demands to being more proactive and considering whole system value.

Keywords: Health technology assessment, Patient participation, Stakeholder engagement, Financial management, Value-based purchasing

Often, the purpose of health technology assessment (HTA) is to inform decisions about the coverage/reimbursement and use of new and existing health interventions, typically within health systems with limited resources to acquire and deliver them (1). HTA should be tailored to the types of decisions it is informing and reflect the needs and realities of the health and innovation systems within which it is operating. This is reflected in a growing recognition that it should take account of the lifecycle of health system innovation to be more impactful $(2 ; 3)$.

In recent years, there have been fundamental changes in approaches to health system delivery, influenced by increasing public demand and patient influence, limited resources, new governance models, developments in information and communication technology, and new service delivery models seeking to improve quality and efficiency (4). Commercial innovators

The authors acknowledge the leadership of the Policy Forum Committee in steering this work. Members of the committee were Barbara Calvert, Abbott; Joseph Cook, Pfizer Inc.; Wim Goettsch, National Healthcare Institute (ZIN), The Netherlands; Ansgar Hebborn, F. Hoffman-La Roche AG; Guy Maddern, University of Adelaide, Australia; and Sean Tunis, Centre for Medical Technology Policy (CMTP), USA. The authors are also grateful to the full list of HTAi Policy Forum attendees who provided feedback on the work (listed in Supplementary Table 1). have similarly created new approaches to technology development, exploiting scientific advances, and working more closely with health system regulators and administrators to develop the evidence of safety and effectiveness that they seek (5).

The Health Technology Assessment international (HTAi) Policy Forum brings together senior people from public and private sector organizations using HTA to support decisions or about product development and coverage for strategic discussions about the present state of HTA, its development, and implications for healthcare systems, industry, patients, and other stakeholders. The discussion at the 2015 Policy Forum suggested "the HTA paradigm needs to be more agile," "helping healthcare systems understand the potential of innovations and to ensure that their potential value is realized" (5). For HTA to deliver this enhanced role, HTA needs to innovate along with current health and innovation system developments, and changing ways that health systems and society view concepts of value and affordability (5).

\section{METHODS}

The broad theme of innovation in HTA for the 2016 Policy Forum meeting was identified through discussion at and 
Husereau et al.

Table 1. Changing HTA Paradigm: A Step Shange in HTA

Current HTA approach

Innovating in HTA

Patient involvement
Focus on the technology (single and multiple technology assessments)
Unilateral stakeholder liaison (manufacturer-regulator), absence of
service delivery
Focus on "front end" innovation
Scientific advice
Review of submitted evidence
Data/evidence for regulatory approval

Continued methodological development

HTA meaningful for regulators and payers

Analysing organizational implications

HTA process complex and time consuming

Static HTA: a single episode at one point in life cycle

HTA confined to assessment of health technologies

HTA and value of innovations

HTA linked with payers

HTA in a budgetary and health system decision making with a short-term perspective
Patient driven priorities

Focus on disease pathology and patient pathway

Multi-lateral stakeholder dialog and collaboration, including health service delivery perspective

Whole technology life cycle, from entry to exit

Scientific dialogue

Aligned, co-produced, real-time, real world data

Data/evidence for holistic value assessment (regulatory, payer and health service delivery)

Continued methodological development

Translation of outputs of HTA in clinical practice (meaningful for clinicians and patients) Enhancing the reach of HTA to clinical practice

Better integration and information of service delivery issues and planning (add info on what is needed in healthcare system to deliver)

HTA process agile and adaptive across the life cycle

Dynamic HTA: continuous/updated assessment. System and resources keep pace as data

become available and when/if things change during the life cycle

HTA beyond the confines of traditional HTA using its approach to support and improve healthcare service

HTA and value and affordability of innovations (how health system can have the capacity to absorb the current and projected level of innovations)

HTA linked with health system, with those responsible for allocating resources. HTA as a convenor of all parties on how health system needs to develop to get value from innovation

HTA taking a medium long-term perspective in informing health system decision making following the 2015 meeting. The scope, title, and detailed agenda for the meeting were then developed through email and face-to-face discussions between members of the Policy Forum and a smaller leadership group (the Policy Forum committee).

The 2016 HTAi meeting was held from January 31 to February 2 in San Francisco, California. Sixty-one people participated in the discussion, including Policy Forum and HTAi Board members and invited thought-leaders in health services leadership and patient advocacy (Supplementary Table 1). A background paper was developed to support discussion and several case studies were briefly described in this, with further detail presented at the meeting.

The meeting was conducted under the Chatham House Rule (6), whereby participants are free to share information obtained at the meeting, but they may not reveal the identity or affiliation of the person providing the information. This study summarizes the authors' views of the key thoughts and suggestions emerging from the discussion at the meeting and the wider issues raised. While informed and strengthened by attendees' comments on drafts, it is not a consensus statement from the meeting, nor can it be taken to represent the views of any of those attending the meeting or the organizations for which they work.

\section{FINDINGS}

\section{Defining the Focus for the Main Discussion}

During the scoping process leading up to the meeting, various ways in which innovative approaches in HTA can be conceptualized were described (Table 1). It was believed that the changing paradigm in HTA could best be characterized by one or more of the following: more agile and adaptive HTA processes across the life cycle of technologies; assessment methods and language that go beyond incremental costeffectiveness ratios and are meaningful to clinicians and patients; and multi-lateral stakeholder dialog and collaboration that addresses health needs and product conceptualization, 
through development, evaluation, introduction, and appropriate use in the midst of other developments.

Drawing on these discussions, five key areas were identified where innovation in HTA is happening or is needed. These were: (i) HTA engagement with payers and health systems and a move toward more sophisticated approaches to multistakeholder engagement; (ii) New approaches to scientific dialogue, particularly between HTA bodies and industry but also involving other stakeholders including regulators, providers and patients; (iii) How HTA can influence the pipeline and priorities of research and development, either private-sector or public-sector funded; (iv) The use of adaptive/lifecycle approaches to technology management; and (v) The increasing need to use real-world data.

The Forum decided that discussion at the 2016 meeting should be based as far as possible around real-life case studies or work and experiences in member organizations. The meeting should focus on two themes that had not been the main focus of earlier Forum discussions: "Re-thinking scientific dialogue and stakeholder engagement" (a combination of areas 1 and 2 above); and "Re-thinking value, affordability and access" (a theme that emerged only after further discussion).

Exploration of these two themes at the meeting was preceded by a discussion of "HTA at a Crossroads," stimulated by invited keynote presentations from leaders in HTA, industry, health system management and patient advocacy.

\section{HTA at a Crossroads}

The push for a paradigm shift in HTA reflects both changes in health system approaches and in the development of innovation. While both producers and purchasers of health technology share a goal of "improved patient access to valuable innovation" $(7 ; 8)$ satisfying this goal within fiscal constraints means revisiting what innovation is needed (9) and how patients and health systems value innovation (10) as well as the processes that lead to access. HTA is often seen as part of an approach that views patients as a cost burden and technologic innovation as a problem rather than a solution. Proposed innovative approaches to HTA include improved engagement to better understand the value of innovation to patients $(11 ; 12)$ and make better use of information developed before, during, and after the regulatory process (13).

Examples of these HTA innovations include proposals for early scientific dialogue (3), adaptive pathways (17), better use of real-world data (5), and encouraging more innovative product listing agreements (18). Innovators have also innovated, through improved evidence production for payers, organizational changes that better consider payer needs, and coalitions intended to standardize evidence collection and measurement (5). For example, the Agenzia Italiana del Farmaco has recently committed to integrating real world data into HTA activities, with the aim of informing the renegotiation process and aligning prices to the value to the health system (15).

Another key feature in the changing HTA paradigm is increasing the involvement of patients (10). Increasingly, patient and community preferences/values are considered part of the "evidence" in HTA (16), and there has been a significant increase in support for patient-centered research in the United States (17) as well as in global drug development by the private sector. Patients have welcomed these changes, although some have suggested that engaging in the clinical development phase has been more rewarding and presented fewer obstacles than in the HTA phase.

In the following sections of this report, we further examine current changes under the meeting main themes, and the implications of each.

\section{RE-THINKING SCIENTIFIC DIALOGUE AND STAKEHOLDER ENGAGEMENT}

\section{Theory and Principles}

Beyond an increasing realization that patients need to be involved in early and ongoing scientific dialogue, in addition to assessments of a technology at any specific time, is work to develop and implement "fast track" regulatory approaches and calls for "adaptive licensing" (18). This has led to the recognition that all regulatory and HTA bodies need to work together, and with patients, if these approaches are to achieve their goals of giving patients faster and more appropriate access to promising new technologies (17).

More recently, there has been recognition of the need for HTA to work more closely with a range of other stakeholders, particularly care providers, health system administrators, and health service managers at relevant levels in the healthcare system, including those responsible for policy and decisions on access and reimbursement at both national and local levels, and those responsible for delivery of a new technology who can advise on and need to be aware of the likely impact on current pathways and systems (5).

Other increased engagement is seen with some jurisdictions moving from "traditional" clinical practice guidelines that pay little or no attention to costs to guidelines or care pathways that address this and broader system concerns. This has required clinicians, HTA bodies, managers, and patients to work together. Some of these initiatives have been born out of quality improvement initiatives that attempt to link payment and delivery to value and through using disease-specific strategic or managed clinical networks (19). Another significant driver in this effort is an increasing interest in hospital-based HTA approaches.

These activities highlight the need for engaging multiple stakeholders in early and ongoing dialogue as a means to 


\begin{tabular}{|c|c|c|c|}
\hline Theme & $\begin{array}{l}\text { Case study } \\
\text { Challenges for patient access }\end{array}$ & Proposed change to current HTA paradigm & Positive impact on access? \\
\hline \multirow[t]{3}{*}{$\begin{array}{l}\text { Re-thinking scientific } \\
\text { dialogue and stakeholder } \\
\text { engagement }\end{array}$} & $\begin{array}{l}\text { Coordinated early dialogue among European jurisdictions and a } \\
\text { medical innovator of pulmonary artery pressure monitoring for } \\
\text { heart failure management. Objectives were to discuss } \\
\text { non-binding evidence requirements for HTA for a technology that } \\
\text { requires funding for community-based information technology } \\
\text { and remote care. }\end{array}$ & HTA bodies, and industry engagement & Some \\
\hline & $\begin{array}{l}\text { A newly introduced process for including Swedish county council } \\
\text { payers in dialogue with industry and the HTA body about the } \\
\text { assessment of prescription drugs in Sweden. Intended to create } \\
\text { system readiness and reduce inequity to access across counties. }\end{array}$ & $\begin{array}{l}\text { Industry, HTA bodies and payer } \\
\text { engagement }\end{array}$ & Yes \\
\hline & $\begin{array}{l}\text { A non-jurisdictional initiative intended to examine the feasibility of } \\
\text { consensus evidentiary requirements across HTA bodies / payers } \\
\text { for new drugs for Alzheimer's disease. Intended to guide clinical } \\
\text { development of new agents. }\end{array}$ & $\begin{array}{l}\text { Industry, regulators and clinician } \\
\text { engagement }\end{array}$ & $\begin{array}{l}\text { To be determined } \\
\text { Change in clinical } \\
\text { development plans }\end{array}$ \\
\hline \multirow[t]{3}{*}{$\begin{array}{l}\text { Rethinking Value, } \\
\text { Affordability and Access }\end{array}$} & $\begin{array}{l}\text { A US, publically (federally)-funded, patient-centered research } \\
\text { initiative to address unanswered questions for patients, } \\
\text { providers and payers surrounding the use of (high fiscal impact) } \\
\text { drugs for chronic hepatitis ( virus infection. }\end{array}$ & $\begin{array}{l}\text { Fund additional evidence production } \\
\text { based on patient engagement }\end{array}$ & To be determined \\
\hline & $\begin{array}{l}\text { Theoretical case study exploring the use of deep brain stimulation } \\
\text { for Alzheimer's disease, which represents a significant increase } \\
\text { in current utilization for a high-cost technology requiring } \\
\text { significant limited speciallist surgeons and allied health } \\
\text { professionals. Intended to illustrate system readiness for large } \\
\text { upfront investments and challenges with collecting payer } \\
\text { evidence for medical devices. }\end{array}$ & $\begin{array}{l}\text { None proposed but could require one or } \\
\text { more approaches }\end{array}$ & To be determined \\
\hline & $\begin{array}{l}\text { The Institute for Clinical Effectiveness Review framework for } \\
\text { re-examining the price of high-value, high budget impact drugs } \\
\text { requiring significant upfront investment. Intended to help current } \\
\text { payers negotiate prices based on capacity for funding. }\end{array}$ & $\begin{array}{l}\text { Additionally examine value in terms of } \\
\text { affordability }\end{array}$ & Yes \\
\hline
\end{tabular}

facilitating access to valuable innovation. However, they raise issues as to whether HTA bodies or others are best suited to convene and coordinate such discussions, and whether HTA bodies have the skills, resources, and authority to take on such a role.

\section{Examples/Cases}

Three case studies were presented that provided different insights into the opportunities and challenges of stakeholder engagement (Table 2). Each case highlighted the issues of engaging different types of stakeholders, in different jurisdictional contexts and for different purposes. Each case also highlighted the desirability of multi-stakeholder engagement but the need for further clarity and processes to improve approaches during and after implementation. They also highlighted that time is needed to create a "shared language" across stakeholders and even between the same stakeholders.

\section{Summary of Discussion: Dialogue and Engagement}

Participants noted that engagement and dialogue are important not only for optimizing the use of health technology but health system performance as a whole. Choices in health service delivery impact a wide number of stakeholders, from the general public, to patients, caregivers, and innovators.

However, dialogue is resource intensive, and stakeholders are numerous, so efficient approaches to engagement must be considered. First, priorities regarding what technologies or conditions require more engagement must be set. This could also involve determining the levels of effort required for some topics depending on perceived impact (analogous to the "rapid" HTA review approach today) (20). Some participants suggested that 
these priorities should also take into account the technological lifecycle as well as the various levels of policy and decision making. However, there are still challenges with lifecycle approaches that require resolution, including the need to consider all current and future innovations and how to disinvest in lowvalue innovations. They will also likely require time-intensive appropriate feedback and re-visiting of decisions.

Second, the geographical level of the dialogue needs to be considered. Some may be required at regional/local levels while other is more suitable at national and supra-national levels. Also, consideration needs to be given to the type and breadth of stakeholders who need to be involved in any particular dialogue. As noted above, this raises questions about who is best suited and adequately resourced to prioritize and coordinate engagement across different levels of decision making and types of stakeholders. It also begs the question as to how impactful various types of engagement are in different situations; recent initiatives are delivering some learning here, but there are still many gaps and it not clear who is, or should be, pulling all this together.

In this context, some participants proposed that a triaged approach might be a more efficient and helpful way forward. This could involve arriving at a consensus on what future areas (defined by therapeutic class, disease or other meaningful characteristics) for technology investment will likely have the largest impact and then engaging in very early international dialogue and consensus between national stakeholders on key information requirements for payers. Stakeholders could agree on the perceived need for technology, what investment is possible, and what evidentiary standards are required. This is a fundamental shift from reactive dialogue initiated by companies to proactive dialogue initiated by HTA/health systems. An example of this approach was the one attempted by Green Park Collaborative International's (21) discussion of HTA and payer's evidence requirements for new technologies for Alzheimer's disease in advance of any such technologies being close to market. Although it proved difficult to reach consensus amongst HTA bodies and payers on evidentiary requirements for classes of drugs that were not yet being considered by regulators, this exercise gave some insight into how, with suitable procedures in place and recognition of the need to preserve the need for autonomy for national and/or local decision makers, discussion at an international level might be pursued.

Another issue arising from the discussion was engagement with the appropriate kinds of stakeholders. While much has been done to engage patients and those close to them, these activities are sometimes misunderstood as engaging the public or citizenry, who may have different roles in reimbursement policy. Patients have knowledge about living with a condition and can discuss what they see as the priorities for their care and the positive and negative aspects of new or existing therapies that may not be captured in the published literature and may be seen as relevant by HTA organizations. In parallel with this, patient advocates may make the case for the priority that should be given to improving care for a particular group of patients $(22 ; 23)$. In contrast, citizens may need to be engaged to help decision makers balance the needs and demands of various different patient groups. Approaches to citizen engagement include appointment of "public" members to committees and/or citizen's juries to more robustly capture the diversity of views and social values (24).

Finally, this discussion highlighted the need for increased trust and confidence between stakeholders and which type of body is best suited to the role of convening the wide ranging, early, and ongoing multi-stakeholder that is being proposed. The cases presented at this meeting highlighted that some HTA organizations have been highly effective in increasing engagement with patients, industry (e.g., through early scientific dialogue), and healthcare administrators in recent years and may now be positioned to build on these experiences to convene engagements to define what innovation is valuable to patients and how to improve access to it.

Although it was clear to meeting participants that HTA bodies need to become the "champions" of value, through supporting payers and decision makers with regard to access, questions did remain as to whether HTA bodies can successfully act as convener or broker of multi-stakeholder engagement, and what approaches are needed to ensure the process is efficient and effective. Some noted that public health or other government bodies that already coordinate research about disease burden and health planning using real-world data may be better suited and resourced to facilitating this kind of engagement.

\section{RETHINKING VALUE, AFFORDABILITY, AND ACCESS}

\section{Theory and Principles}

Value is typically defined by what additional benefits to patients, those close to them, or wider society will gain from the use of innovation and what they are willing to give up (i.e., the opportunity cost) to do so. Traditional approaches to examine value include analyses of cost-effectiveness, often with universal measures of health such as quality-adjusted life-years compared with the value of resources required, to provide decision makers with a sense of economic value (i.e., what must be given up to obtain benefits). Cost-effectiveness has become a key criterion in developed jurisdictions to inform reimbursement decisions.

A recent concern is that this approach does not consider either expenditure or technology growth, or the affordability of new technology, arguably a more direct measure of lost opportunity for payers. Some technologies with high value (according to traditional cost-effectiveness evaluation) and high budget impact are now not being fully reimbursed due to problems of affordability in developed systems, a problem until recently only faced by developing countries. While new products for 
chronic hepatitis $\mathrm{C}$ virus infection and oncology are the main focus for this debate currently, payers (and producers) are concerned about therapies for Alzheimer's prevention, some medical devices, in vitro gene therapy, and other regenerative therapies as they look to the future (25).

There have been several responses or proposed solutions to the introduction of therapies of potentially high value and high and potentially unmanageable budget impact: one is a traditional approach to managing funding through limiting access to identifiable subgroups where therapy is most cost-effective (26), and/or developing care pathways or rationing sequences of use (e.g., first line, second line therapy). An example of restriction is with new hepatitis $\mathrm{C}$ treatments, where despite receiving a $50 \%$ discount on the price, the US Department of Veterans' Affairs had to restrict reimbursement to a proportion of their constituents infected with the virus (27).

Another response that is that of using product-listing agreements that can be put in place to address payer uncertainty about effectiveness, or cost-effectiveness or budget impact, or some combination of these. In some cases, innovative access with evidence development or "performance-based risk sharing" agreements have been used (28). These have been discussed extensively in previous Policy Forum meetings and elsewhere (although the focus in many of those discussions has been more on value than affordability) (18).

A further approach is a call for "financial innovation" approaches such as licensing and bond mechanisms (29). For example, USD 6.5 billion from twenty-three countries was raised by The International Finance Facility for Immunization scheme which was used to provide vaccines to countries with a lesser ability to pay more rapidly (30). Other examples include social impact bonds that provide long term rewards to innovators for the performance of their innovations $(29 ; 31)$.

A final response to challenges of affordability has been to try to work issues of overall cost and budget impact into formal frameworks for assessing what is should be reimbursed (32). This has ranged from improving the structure and transparency of existing deliberative processes for appraisal to incorporating or investigating additional metrics that may reflect wider social benefits when considering the value of investing in healthcare interventions. One proposed approach is multi-criteria decision analysis (MCDA) as a means of combining a range of factors relevant to defining and determining value (33). Some MCDAbased proposals have addressed the payer's problem of scarce resources, while others do not explicitly consider opportunity costs (34). MCDA approaches require additional administrative burden and are not mainstream but have seen some uptake in Thailand and Europe (35).

Not surprisingly, these developments have led to debate about what represents value and a "fair price" for a technology, that is, a price that provides a good return to investors, rewards and incentivizes innovation, and allows society to benefit to the full from the uptake of the technology. It also raises questions about the relationship between policies directed at pricing and innovation.

In the developing world, where questions of value and affordability have long been key, some jurisdictions have adopted more radical solutions. This can include demanding dramatic discounts or implementing systems of voluntary or compulsory licensing. In some cases, patent systems intended to reward innovation have been ignored or the practice of parallel trade has been allowed to provide better access to technologies but at greatly reduced prices.

\section{Examples/Cases}

Three case studies were presented that provided different insights into the challenges of technologies with favorable costeffectiveness but that present challenges around affordability. One case focused on new drugs for chronic HCV infection. A second presented an analogous and hypothetical case for a medical device for Alzheimer's disease. A third case study described a new value framework that considers affordability as a means to guide payer decisions on coverage and price.

\section{Summary of Discussion: Value, Affordability, and Access}

Policy Forum participants discussed the concepts of value and affordability, the relationship between them, and role of HTA in the assessment of them and in decision making based upon them. Some emphasized the differences between affordability and value and the roles they should play in decision making about new technologies. Concerns were expressed that a focus simply on affordability could lead to value as currently assessed through HTA being overlooked and that this could have a detrimental impact on valuable innovation and patient access to new treatments. Others suggested value can and should consider affordability but this does not mean simply searching for the lowest price, care must be taken to maximize efficiency in innovation system as well the health system. In this way, HTA could still play an important role in facilitating the development of evidence to support effective investment/disinvestment decisions. However, some participants noted that many payers have no incentive to think about incremental innovation or dynamic efficiency, as they are ultimately rewarded for getting the best price. Likewise, producers may have little incentive to think about the collective effects of innovation on health system budgets or the overall health of nations.

Whether notions of affordability are or are not embraced by HTA bodies does not remove the need for wider societal debate regarding what health systems can afford and how we will pay for "good value" technologies. It has frequently been suggested that there is an important role for HTA to identify low-value healthcare activities to support disinvestment to free up resources for new higher value activities (36). Despite theoretical appeal, however, there are various practical challenges: exercises of this kind have had limited success in identifying 
low value activities, eliminating such activities is often politically difficult, and much of the expenditure growth in health care appears to be driven by growth in the volume of evidencebased care, not a "disproportionate growth in wasteful care" (37).

There was also considerable discussion about a role for enhanced horizon scanning as a means of helping to address challenges around affordability and access. Some participants noted that the largely reactive responses to HCV therapies today might have been better informed through a horizon scanning process that supported upstream projection and planning by multiple stakeholders. This also highlights the need for horizon scanning that can promote downstream action, discussions and information from scanning is not useful if agreed policies and plans are not implemented on the ground. An enhanced approach to horizon scanning would, therefore, require the engagement of more stakeholders, with cross-industry involvement and ongoing discussions from early the technology development process through to implementation.

This approach to horizon scanning has much in common with the new approach to ongoing, multi-stakeholder dialogue discussed in the previous section of this study. Not surprisingly, therefore, the issue was again raised as to whether HTA bodies are most appropriately placed to convene these discussions or whether other institutions/bodies (e.g., manufacturers themselves, independent bodies, or other government bodies) might be better placed to do this. Participants also suggested that none of these activities should be seen as replacing standard HTA activities that address the value and impact of current technologies.

Through this discussion some key questions were raised. All seem to agree that HTA bodies must continue to assess and advise on value, but further discussion is needed of the role, if any, that HTA bodies can and should play in supporting decisions on what is affordable, and in supporting enhanced horizon scanning, dialogue and planning. And what role can and should industry play in stimulating, convening or leading these activities? The ongoing success of the health innovation and delivery systems, and the health of the public depend on industry, health systems, governments, and societies finding solutions to these challenges, with the help of HTA bodies, regulators and other key parts of the system.

\section{CONCLUDING REMARKS}

The discussion by the Policy Forum ultimately highlighted that it is still "early days" for changing HTA paradigms but we have begun to see change. The discussion of value, affordability and access in highlighted that health systems in developed economies have increasingly had to consider budget impact and affordability as well as value. Various tools are available to manage introduction, access, cost, and budget impact, but challenges will remain. Improved horizon scanning followed by effective dialogue and planning between health system and industry could help these to be better addressed. There was agreement that HTA bodies must continue to assess value, but there was a range of views on the role HTA could and should play in assessing or supporting discussions on affordability.

The prevailing view in the meeting was any approach to considering affordability should also be part of a wider and earlier ongoing dialogue. Although early "scientific" dialogue is increasingly becoming established and helping improve the speed and quality of assessment and coverage decisions of new technologies, there is still a need for engaging all relevant stakeholders (industry, regulators, HTA bodies, payers, clinicians, health service managers, patients) at all stages to improve the targeting of innovation and new technologies on patient and health system needs, and the effective introduction and management of them over their life cycles.

Questions remained whether HTA may be well positioned to do facilitate this broader multi-stakeholder engagement. However, if not a role for HTA, we will need to ask ourselves, "then who?" Some suggested a possible role for other nationally funded bodies with a health focus, such as public health bodies, regulators, or research funders. Others suggested new bodies are required, as is now seen with research and innovation councils in some jurisdictions. Nonetheless, HTA bodies could work toward being true champions of value through better coordination and adherence to principled approaches. HTAi could play a role in brokering international discussions between industry, regulators, public health bodies, HTA and payer bodies, and patient representatives to identify the next steps in promoting early and ongoing international dialogue around technologies, and particularly classes of technologies and/or disease areas, building on and learning from the experience in ongoing single and multi-jurisdiction early scientific dialogue initiatives, and wider international work such as Green Park.

These changing HTA paradigms do not also change HTA's fundamental remit of being responsive to decision makers and improving the capacity of the health system to benefit from technology. It also does not change the principle of needing to conduct HTA in manner "fit for purpose," that is, although how and who and when this might happen will vary according to the various health systems that have been implemented globally. In some cases HTA may be well suited to take on a leadership role while in others, it may not. A reasonable next step is for HTA bodies and producers to ask this question in their own health jurisdictions, so as to either further establish the role of HTA or ensure that an appropriate actor is leading this activity.

Questions of value implicitly raise fundamental questions about societal choice. Certainly patients will need to be part of better engagement. And although patients are increasingly playing a role in defining what is valuable through participating in HTA processes, some have suggested that the limited time and resources that patients have at their disposal may best be spent influencing "up-stream" discussions on the targeting of 
innovation and selection of new technologies to develop, and the design of trials to demonstrate their value.

Ultimately, access to all technology regardless of cost is not appealing to current health system stewards, and without better engagement, questions remain as to what societies true preferences are for investments in healthcare. It is possible that some societies do not want to allocate extra resources to new (but valuable) technologies in the end. These questions are important to future innovation. In many jurisdictions, these questions are being answered by self-directed researchers rather than through applied government research. Whatever the means, an increased focus on choice will ultimately require consideration of what society is willing to pay and give up for health innovation. This means changing HTA paradigms will extend HTA's traditional remit of being responsive to decision-makers demands to being more proactive and considering whole system value.

\section{SUPPLEMENTARY MATERIAL}

Supplementary Table 1:

http://dx.doi.org/10.1017/S0266462316000386

\section{CONFLICTS OF INTEREST}

The authors were funded by HTAi to organize and report on this meeting. In addition, Don Husereau and Chris Henshall have undertaken a range of other paid work relating to HTA with consultancies, not-for-profit organizations and governments.

\section{REFERENCES}

1. OECD. Value for Money in Health Spending [Internet]. Paris: Organisation for Economic Co-operation and Development; 2010 [cited February 4, 2015]. http://www.oecd- ilibrary.org/content/book/ 9789264088818-en

2. Frønsdal KB, Facey K, Klemp M, et al. Health technology assessment to optimize health technology utilization: Using implementation initiatives and monitoring processes. Int J Technol Assess Health Care. 2010;26:309-316.

3. Henshall C, Schuller T; HTAi Policy Forum. Health technology assessment, value-based decision making, and innovation. Int J Technol Assess Health Care. 2013;29:353-359.

4. Mossialos E, Wenzl M, Osborn R, Sarnak D, eds. International profiles of health care systems, 2015 [Internet]. The Commonwealth Fund; 2016 [cited March 14, 2016]. http://www.commonwealthfund.org/ publications/fund-reports/2016/jan/international-profiles-2015

5. Facey K. Improving the effectiveness and efficiency of evidence production for HTA in the light of current trends in drug and device development, health system funding, regulation and HTA. Int J Technol Assess Health Care. 2015;31:201-206.

6. Chatham House Rule [Internet]. Chatham House. [cited March 14, 2016]. https://www.chathamhouse.org//node/44

7. Europe Decides. What can the EU do to improve access to medicines? [Internet]. 2015 [cited March 14, 2016]. http://europedecides.eu/2015/ 02/what-can-the-eu-do-to-improve-access-to-medicines/

8. EFPIA - Improving patient access to innovative medicines - the framework in which differentiated pricing may offer a solution
[Internet]. [cited March 14, 2016]. http://www.efpia.eu/documents/102/ 48/Improving-patient-access-to-innovative-medicines-the-frameworkin-which-differentiated-pricing-may-offer-a-solution

9. Kennedy I. Appraising the value of innovation and other benefits [Internet]. 2009. https://www.nice.org.uk/Media/Default/About/what-we-do/ Research-and-development/Kennedy-study-final-report.pdf

10. Dirksen CD. The use of research evidence on patient preferences in health care decision-making: Issues, controversies and moving forward. Expert Rev Pharmacoecon Outcomes Res. 2014;14:785-794.

11. Ward JW, Mermin JH. Simple, effective, but out of reach? Public health implications of HCV drugs. N Engl J Med. 2015;373:2678-2680.

12. Eichler H-G, Pignatti F, Flamion B, Leufkens H, Breckenridge A. Balancing early market access to new drugs with the need for benefit/risk data: A mounting dilemma. Nat Rev Drug Discov. 2008;7:818-826.

13. Husereau D, Henshall C, Jivrai J. Adaptive approaches to licensing, health technology assessment, and introduction of drugs and devices. Int J Technol Assess Health Care. 2014;30:241-249.

14. Klemp M, Frønsdal KB, Facey K. What principles should govern the use of managed entry agreements? Int J Technol Assess Health Care. 2011;27:77-83.

15. Montilla S, Xoxi E, Russo P, Cicchetti A, Pani L. Monitoring registries at Italian medicines agency: fostering access, guaranteeing sustainability. Int J Technol Assess Health Care. 2015;31:210-213.

16. Facey KM, Hansen HP. Patient-focused HTAs. Int J Technol Assess Health Care. 2011;27:273-274.

17. Frank L, Forsythe L, Ellis L, et al. Conceptual and practical foundations of patient engagement in research at the patient-centered outcomes research institute. Qual Life Res. 2015;24:1033-1041.

18. Eichler H-G, Bloechl-Daum B, Abadie E, et al. Relative efficacy of drugs: An emerging issue between regulatory agencies and third-party payers. Nat Rev Drug Discov. 2010;9:277-291.

19. Lord J, Willis S, Eatock J, et al. Economic modelling of diagnostic and treatment pathways in National Institute for Health and Care Excellence clinical guidelines: The Modelling Algorithm Pathways in Guidelines (MAPGuide) project. Health Technol Assess. 2013;17:v-vi, 1-192.

20. Noorani HZ, Husereau DR, Boudreau R, Skidmore B. Priority setting for health technology assessments: A systematic review of current practical approaches. Int J Technol Assess Health Care. 2007;23:310-315.

21. greenparkcollaborative - Alzheimer's Disease Pilot [Internet]. [cited May 9, 2014]. http://www.cmtpnet.org/resource-center/view/designof-clinical-studies-of-pharmacologic-therapies-for-alzheimers-diseas/

22. Low E. Potential for patients and patient-driven organizations to improve evidence for health technology assessment. Int J Technol Assess Health Care. 2015;31:226-227.

23. Moreira T. Understanding the role of patient organizations in health technology assessment. Health Expect. 2015;18:3349-3357.

24. Whitty JA. An international survey of the public engagement practices of health technology assessment organizations. Value Health. 2013;16:155163.

25. Husereau D. How do we value a cure? Expert Rev Pharmacoecon Outcomes Res. 2015;15:551-555.

26. Coyle D, Buxton MJ, O'Brien BJ. Stratified cost-effectiveness analysis: A framework for establishing efficient limited use criteria. Health Econ. 2003;12:421-427.

27. 1 CRCND, 2015, Pm 7:23. VA can't afford drug for veterans suffering from hepatitis C [Internet]. [cited December 3, 2015]. http://www.cbsnews.com/news/va-cant-afford-drug-for-veteranssuffering-from-hepatitis-c/

28. Carlson JJ, Sullivan SD, Garrison LP, Neumann PJ, Veenstra DL. Linking payment to health outcomes: A taxonomy and examination of performance-based reimbursement schemes between healthcare payers and manufacturers. Health Policy. 2010;96:179-190. 
29. The way forward on social impact bonds [Internet]. MaRS. [cited November 30, 2015]. https:/www.marsdd.com/news-and-insights/ way-forward-social-impact-bonds-canadian-impact-investors-giveinsights-new-report/

30. Overview - ABOUT IFFIm - International Finance Facility for Immunisation [Internet]. [cited February 14, 2015]. http://www.iffim.org/About/ Overview/

31. The Health Impact Fund: A Summary Overview | Incentives for Global Health [Internet]. [cited February 14, 2015]. http://healthimpactfund. org/publications/

32. Daniels N, Porteny T, Urritia J. Expanded HTA: Enhancing fairness and legitimacy. Int J Health Policy Manag. 2015;5:1-3.

33. Thokala P, Duenas A. Multiple criteria decision analysis for health technology assessment. Value Health. 2012;15:1172-1181.
34. Diaby V, Goeree R. How to use multi-criteria decision analysis methods for reimbursement decision-making in healthcare: A step-by-step guide. Expert Rev Pharmacoecon Outcomes Res. 2014;14:81-99.

35. Thokala P, Devlin N, Marsh K, et al. Multiple criteria decision analysis for health care decision making-An introduction: Report 1 of the ISPOR MCDA Emerging Good Practices Task Force. Value Health. 2016;19:113.

36. Henshall C, Schuller T, Mardhani-Bayne L. Using health technology assessment to support optimal use of technologies in current practice: The challenge of "disinvestment." Int J Technol Assess Health Care. 2012;28:203-210.

37. Garber AM. Cost-effectiveness and evidence evaluation as criteria for coverage policy. Health Aff (Millwood). 2004 Jan-Jun;Suppl Web Exclusives:W4-284-296. 